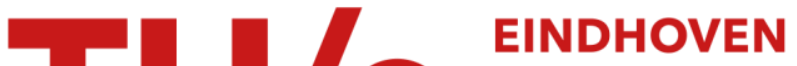

\section{Determination of Young's modulus or Poisson's ratio using eddy currents}

Citation for published version (APA):

Kwaaitaal, T., \& Schoofs, A. J. G. (1979). Determination of Young's modulus or Poisson's ratio using eddy currents. Experimental Mechanics, 19(12), 450-455.

Document status and date:

Published: 01/01/1979

\section{Document Version:}

Publisher's PDF, also known as Version of Record (includes final page, issue and volume numbers)

\section{Please check the document version of this publication:}

- A submitted manuscript is the version of the article upon submission and before peer-review. There can be important differences between the submitted version and the official published version of record. People interested in the research are advised to contact the author for the final version of the publication, or visit the $\mathrm{DOI}$ to the publisher's website.

- The final author version and the galley proof are versions of the publication after peer review.

- The final published version features the final layout of the paper including the volume, issue and page numbers.

Link to publication

\section{General rights}

Copyright and moral rights for the publications made accessible in the public portal are retained by the authors and/or other copyright owners and it is a condition of accessing publications that users recognise and abide by the legal requirements associated with these rights.

- Users may download and print one copy of any publication from the public portal for the purpose of private study or research.

- You may not further distribute the material or use it for any profit-making activity or commercial gain

- You may freely distribute the URL identifying the publication in the public portal.

If the publication is distributed under the terms of Article 25fa of the Dutch Copyright Act, indicated by the "Taverne" license above, please follow below link for the End User Agreement:

www.tue.nl/taverne

Take down policy

If you believe that this document breaches copyright please contact us at:

openaccess@tue.nl

providing details and we will investigate your claim. 


\title{
Determination of Young's Modulus or Poisson's Ratio Using Eddy Currents
}

\author{
Young's modulus and Poisson's ratio of a small conducting specimen \\ can be determined by a new method using \\ the strains caused by eddy currents in a magnetic field
}

by Th. Kwaaitaal and A.J.G. Schoofs

\begin{abstract}
Combined $a-c$ and $d-c$ magnetic fields cause strains in a conducting sample. The amplitude of this strain is dependent on the value of Young's modulus and Poisson's ratio. The strain amplitude, being in the order of $10 \mathrm{pm}$, can be measured with a stabilized Michelson interferometer, described elsewhere. ${ }^{12}$ An expression is derived, relating the axial strain in cylindrical samples to the magnetic-field quantities, the elastic properties and the electrical resistivity of the sample

The finite-element method is used to treat more complicated configurations. Samples of aluminum, copper, gold and tin are used for comparing the measured and calculated results. To this end, the elastic properties of the copper samples were also determined from measurement of the ultrasonic-wave velocity. The agreement between both methods is very satisfactory.
\end{abstract}

\section{List of Symbols}

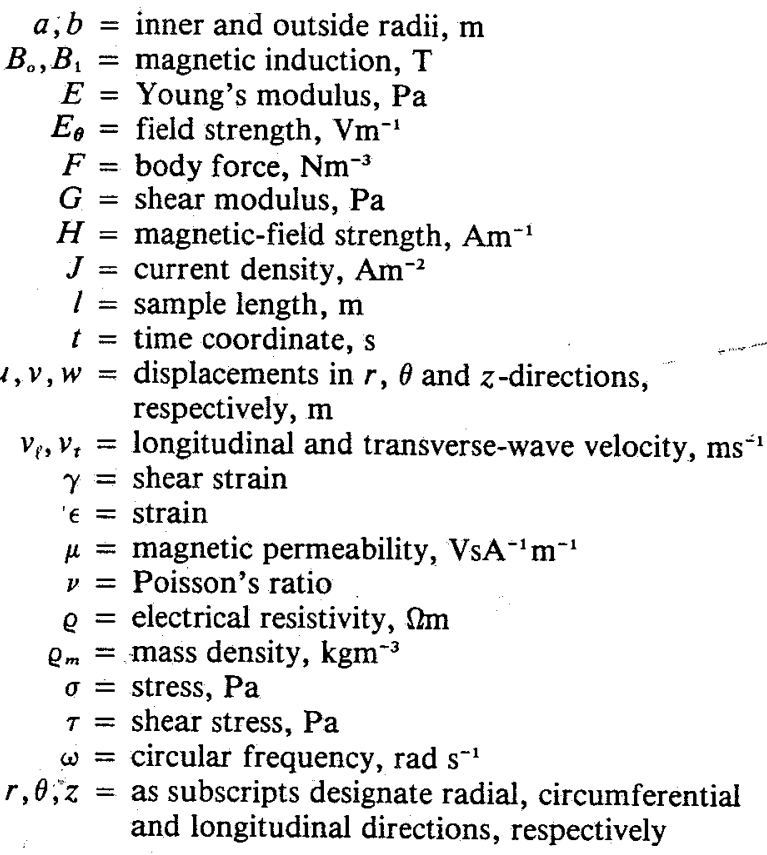

\section{Introduction}

The method described in this paper arose from a

\footnotetext{
Th. Kwaaitaal and A.J.G. Schoofs are associated with Eindhoven University of Technology, Department of Electrical Engineering, Eindhoven, The Netherlands.
}

Original manuscript submitted: March 14, 1979. Final version accepted: June $15,1979$. procedure used to calibrate the amplitude of picometer vibrations measured with a stabilized Michelson interferometer. Such an interferometer is electronically stabilized against drift of thermal origin and can be used to measure vibrational amplitudes as small as $0.08 \mathrm{pm} .^{1}$ Usually, the amplitude of such vibrations is determined by comparison with that of vibrations exhibited by a calibrated piezoelectric crystal. Measurement of magnetostrictive effects, however, entails calibration, including the a-c and d-c magnetic fields needed in this case. Although these fields may be measured by other methods, i.e., the Hall effect and the voltage induced in a coil, an alternative method of measurement is valuable as it gives an indication of possible systematic errors. Such calibration, including the magnetic fields, is found by the use of a conducting sample in which eddy currents are generated by the a-c component of the magnetic field. The d-c component of this field exhibits a Lorentz force on these currents. This force causes an a-c deformation of the sample, the magnitude of which depends on its elastic properties. In the case of common values of magnetic-field strength, elastic properties and electrical conductivities of the sample, this deformation can be measured with sufficient accuracy. As it proves that the two methods give the same results and consequently, that systematic errors are negligible, the procedure can be reversed and used to determine the elastic properties of the sample.

The well-known method of determining the elastic properties of solids by measuring the velocity of ultrasonic waves was used in our experiment.

In the first section of this paper, an expression will be derived for the axial displacement of a cylindrical sample in an axial a-c and d-c magnetic field. The second section is devoted to the comparison of calculated and measured displacements.

The influence of the skin effect will then be discussed since it attempts to disturb the eddy-current distribution in the sample. Finally the merits of the method will be discussed.

It is assumed that the principle of the magnetostriction measurement with the stabilized interferometer is known. Details can be found in Ref. 2 .

\section{The Displacement of a Cylinder in an Axial Magnetic Field}

The geometrical configuration of the sample in the field is given in Fig. 1. Cylinder coordinates are used as indicated in the figure. In calculating the displacement in the $z$-direction, an infinitesimal element of the cylinder 


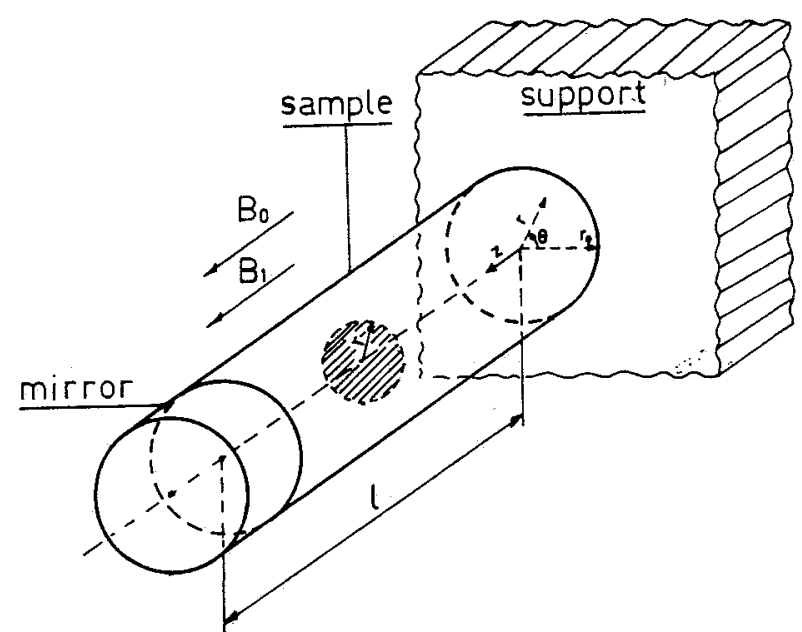

Fig. 1-The position and suspension of the sample relative to the magnetic fields

indicated in Fig. 2 is considered. An expression for the body force $F$ on this element is derived and then the system of equations formed by (1) the equilibrium equations; (2) the strain-displacement relations; and (3) the constitutive equations is solved.

To find an expression for the body force, the integral form of the law of electromagnetic induction is applied to the circular circuit, with radius $r$ drawn about the center axis of the cylinder and shown as a shaded area in Fig. 1 .

$$
\int_{0}^{2 \pi} E_{\theta} r d \theta=-\frac{\partial}{\partial t} \int_{0}^{2 \pi} \int_{0}^{r_{0}} B_{1} r d r d \theta
$$

Here, $E_{\theta}$ is the circumferential field strength induced by the axial a-c magnetic induction $B_{1}$. Inside the circle

Fig. 2-Infinitesimal element of the cylindrical sample and the relevant forces

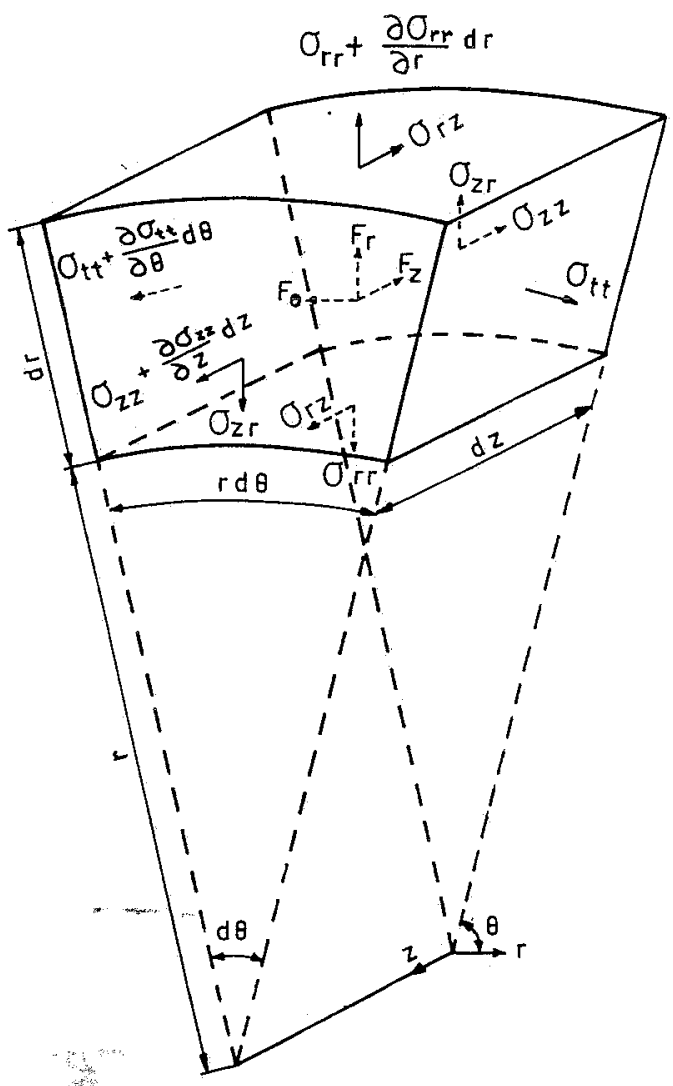

$\left(r<r_{o}\right)$, the field strength equals

$$
E_{\theta}=-\frac{r}{2} \frac{\partial B_{1}}{\partial t}
$$

and thus the current density $J_{\theta}$ defined by $\bar{J}_{\theta}=J_{\theta} \bar{e}_{\theta}$, where $\bar{e}_{\theta}$ is the unit vector in the $\theta$-direction, is given by

$$
J_{\theta}=-\frac{r}{2 \varrho} \frac{\partial B_{1}}{\partial t}
$$

where $\rho$ is the resistivity of the sample, The Lorentz force $\bar{F}_{r}$ on an element with volume $r d r d \theta d z$, resulting from the action on the current of the d-c magnetic field $B_{o}$ defined by $\bar{B}_{0}=B_{o} \bar{e}_{z}$, where $\bar{e}_{z}$ is the unit vector in the $z$-direction, is

$$
\bar{F}_{r}=\bar{J}_{\theta}^{-} \times \bar{B}_{o}
$$

and thus

$$
F_{r}=-\frac{r}{2 \varrho} B_{0} \frac{\partial B_{1}}{\partial t}
$$

while $F_{\theta}$ and $F_{z}$ are both zero.

The relevant equations of equilibrium in cylinder coordinates with axial symmetry can be written as

$$
\begin{gathered}
\frac{\partial \sigma_{r r}}{r}+\frac{\partial \sigma_{r z}}{z}+\frac{\sigma_{r r}-\sigma_{t t}}{r}+F_{r}=0 \\
\frac{\partial \sigma_{r z}}{r}+\frac{\partial \sigma_{z z}}{z}+\frac{\sigma_{r z}}{r}=0
\end{gathered}
$$

The relevant expressions of Hooke's law are

$$
\begin{gathered}
\epsilon_{r r}=\frac{1}{E}\left\{\sigma_{r r}-\nu\left(\sigma_{t t}+\sigma_{z z}\right)\right\} \\
\epsilon_{t t}=\frac{1}{E}\left\{\sigma_{t t}-\nu\left(\sigma_{r r}+\sigma_{z z}\right)\right\} \\
\sigma_{r z}=G \epsilon_{r z}
\end{gathered}
$$

while the strain-displacement relations are

$$
\begin{aligned}
\epsilon_{r r} & =\frac{\partial u_{r}}{\partial r} \quad \epsilon_{r z}=\frac{1}{2}\left(\frac{\partial u_{z}}{\partial r}+\frac{\partial u_{r}}{\partial z}\right) \\
\epsilon_{t t} & =\frac{u_{r}}{r} \\
\epsilon_{z z} & =\frac{\partial u_{z}}{\partial z}
\end{aligned}
$$

In these equations, $\sigma_{i j}$ and $\epsilon_{i j}$ are respectively the stress and the strain acting on the plane $i$ in the direction $j$. The displacements in the radial, tangential and axial directions are indicated by $u_{r}, u_{t}$ and $u_{z}$, respectively.

Solving the equations for a plane-strain situation $\left(\epsilon_{z i}=\right.$ $0)$, the displacement in the axial direction is

$$
u_{z}=-\frac{\nu}{4 \varrho E} B_{o} \frac{\partial B_{1}}{\partial t}\left(1+\frac{a^{2}}{b^{2}}\right) b^{2} l
$$

for the case of a hollow cylinder with inner and outer radius $a$ and $b$, respectively.

For a solid cylinder the displacement is

$$
u_{z}=-\frac{\nu}{4 \varrho E} B_{\circ} \frac{\partial B_{1}}{\partial t} b^{2} l
$$

In the case of plane stress $\left(\sigma_{z x}=0\right)$, the displacement of 
a hollow cylinder is

$$
u_{z}=-\frac{\nu(\nu+3)}{8 \varrho E} B_{a} \frac{\partial B_{1}}{\partial t} b^{2} l\left\{1+\frac{a^{2}}{b^{2}}-2 \frac{\nu+1}{\nu+3} \frac{r^{2}}{b^{2}}\right\}
$$

and, for the solid cylinder,

$$
u_{z}=-\frac{\nu(\nu+3)}{8 \varrho E} B_{o} \frac{\partial B_{1}}{\partial t} b^{2} l\left\{1-2 \frac{\nu+1}{\nu+3} \frac{r^{2}}{b^{2}}\right\}
$$

Assuming that the mirror glued to the sample shows the mean displacement over the surface, eq (10) gives

$$
<u_{z}>=\frac{\int_{0}^{2 \pi} \int_{a}^{b} u_{z} r d r d \theta}{\int_{0}^{2 \pi} \int_{a}^{b} r d r d \theta}=-\frac{\nu}{4 \varrho E} B_{o} \frac{\partial B_{1}}{\partial t}\left(1+\frac{a^{2}}{b^{2}}\right) b^{2} l
$$

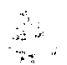

and, for the solid cylinder, eq (11) gives

$$
<u_{z}>=-\frac{\nu}{4 \varrho E} B_{o} \frac{\partial B_{1}}{\partial t} b^{2} l
$$

For evaluating the dependence of $u_{z}$ on $r$ in the planestress condition, a plot of the ratio

$$
\frac{u_{z}}{<u_{z}>}=\frac{\nu+3}{2}\left\{1-\frac{2 \frac{\nu+1}{\nu+3} \frac{r^{2}}{b^{2}}}{1+\frac{a^{2}}{b^{2}}}\right\}
$$

from eqs (10) and (12) is made as a function of $r / b$ for different values of $a / b$ (Fig. 3).

\section{Experimental Evaluation of the Formulas}

To verify the formulas, the displacements $u_{z}$ are measured of four different metals in four different configurations and at ten different values of the product $B_{o} B_{1}$.

The materials used were copper, gold, tin and aluminum. The four different configurations are shown in Fig. 4. Standard dimensions were length $l=10 \mathrm{~mm}$, outer dia-

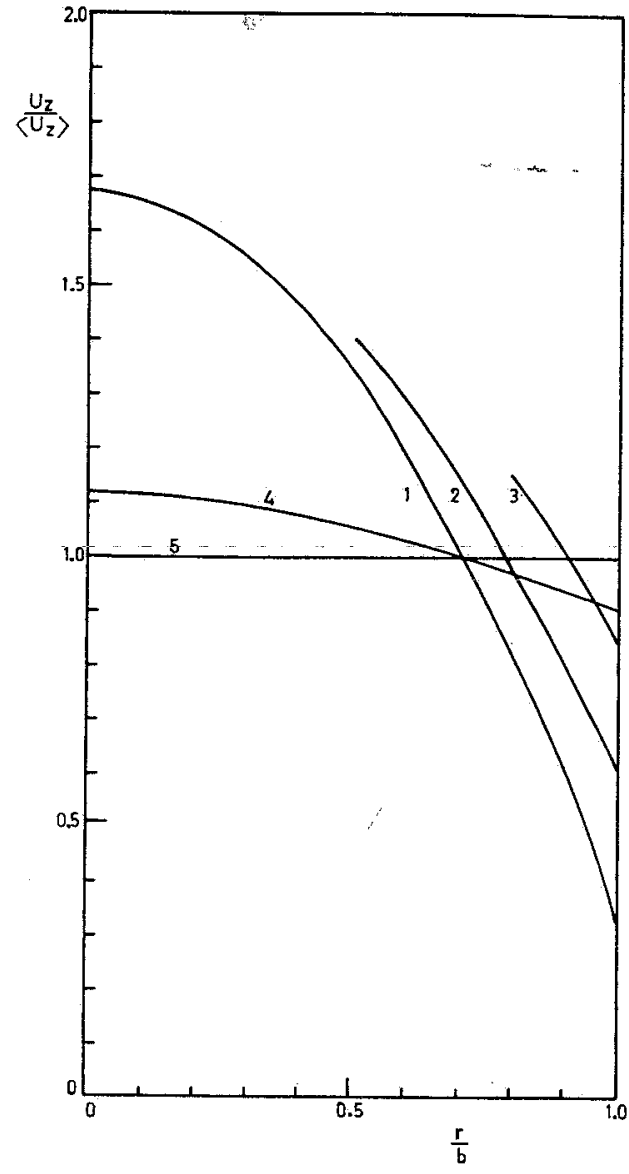

Fig. 3-Plot of the ratio of the axial displacement $u_{z}$ and the mean displacement $\left\langle u_{z}\right\rangle$ as a function of radius $r$. Curves 1,2 and 3 refer to eq (14) with different values of $a / b$, i.e., $0.0,0.5$ and 0.8 . Curve 4 gives the results of a finite-element calculation for a solid cylinder. Curve 5 is the curve for constant strain. In all cases, Poisson's ratio equals 0.35

meter $b=5 \mathrm{~mm}$, inner diameter $a=4 \mathrm{~mm}$, height of stud or $\operatorname{rim} l_{2}=1 \mathrm{~mm}$, thickness of mirror $d=1 \mathrm{~mm}$. Apart from the displacements, the a-c and $d-c$ magnetic fields, the values of Young's modulus and Poisson's ratio and the electrical resistivity were measured. The axial displacement is calculated from these last five measured
Fig. 4-Configurations of the different samples with mirrors. A: solid cylinder; $B$ : hollow cylinder; $C$ : solid cylinder with rim; D: solid cylinder with stud
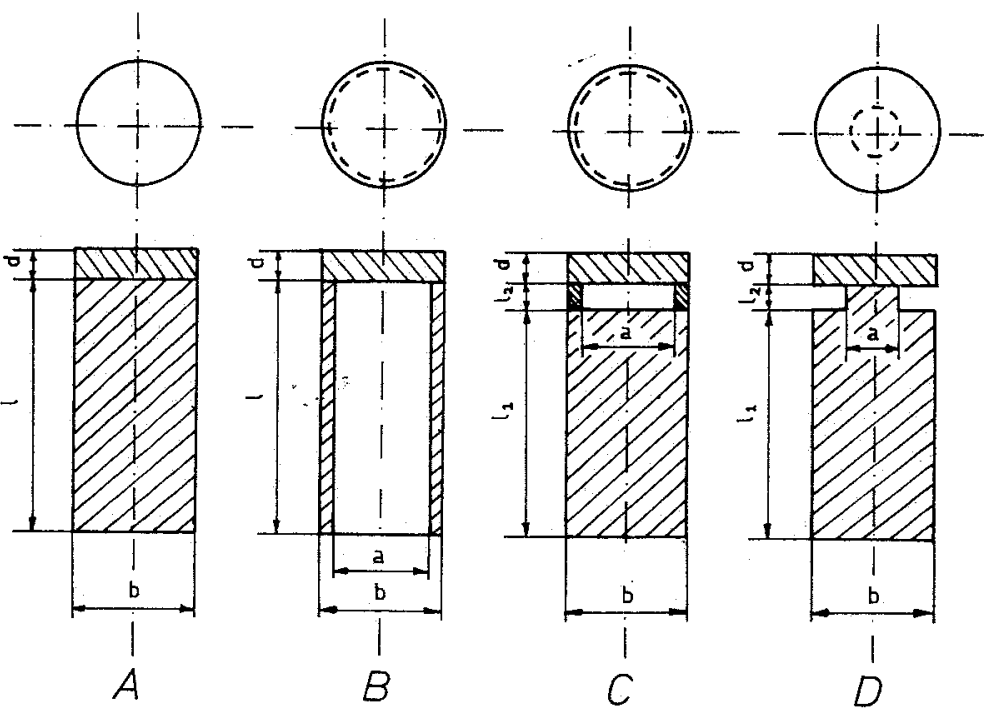
values and from the dimensions of the sample and compared to the measured value.

The value of the d-c field was determined by a Halleffect gaussmeter. The value of the a-c field was determined by placing a coil of the same dimensions as the sample in place of the sample and measuring the induced voltage with a lock-in amplifier.

Ten different values of the product $B_{0} B_{1}$ were obtained by changing the distance between the poles of the electromagnet used at constant a-c and d-c current. The resulting values of $B_{o}$ and $B_{1}$ are given in Table 1. Position 1 of the poles corresponds to a pole distance of $34 \mathrm{~mm}$. The decrease in distance from one position to the next is $1 \mathrm{~mm}$. The frequency of the a-c field is $66 \mathrm{~Hz}$.

The value of Young's modulus and Poisson's ratio for copper were determined by the ultrasonic pulse-echo-overlap method. This was done because quite considerable differences are found in literature on values of Young's modulus.

The sample used for this measurement was a copper cylinder turned from the same piece of material as the sample used for the displacement measurement. It was $49.5 \mathrm{~mm}$ in length and $30 \mathrm{~mm}$ in diameter.

The frequency of the longitudinal waves was $2.3 \mathrm{MHz}$ and their velocity was $4760 \mathrm{~ms}^{-1}$. The frequency of the transverse waves was $4.2 \mathrm{MHz}$ and their velocity 2260 $\mathrm{ms}^{-1}$. Young's modulus and Poisson's ratio were calculated using the formulas

$$
\begin{gathered}
E=4 \varrho_{m} v_{t}^{2} \frac{\frac{3}{4} v_{l}^{2}-v_{t}^{2}}{v_{l}^{2}-y^{2}} \\
\nu=\frac{\frac{1}{2} v_{l}^{2}-v_{t}^{2}}{v_{l}^{2}-v_{t}^{2}}
\end{gathered}
$$

where $\varrho_{m}$ is the mass density of the solid. The accuracy in Young's modulus due to errors in the determination of sample Tength, specific mass and travel time of the waves was estimated to be better than 0.5 percent. The electrical resistivity was determined by a four-point probe method. The values found did not differ from those in literature.

The dependence of the results on the pole distance is given in Table 2 for the copper sample of Fig. 4(d) but with the stud removed. The length of this sample was $9.04 \mathrm{~mm}$. The values of $\varrho, E$ and $\nu$ are as given in Table 3. The results for other samples are given for the value of $B_{o} B_{1}$, corresponding to position 1 of the poles.

The measured displacements of copper, gold, tin and aluminum samples of configuration 4(a) are compared with the values calculated from eqs (9) or (13). The results are tabulated in Table 3.

The dependence of $u_{z}$ on the frequency of the modulating field was examined by repeating the measurements at a frequency of 33 and $132 \mathrm{~Hz}$. The results are shown in Fig. 5. They are measured for a single crystal of copper with the configuration shown in Fig. 4(a) and with the $<111\rangle$ axis oriented along the axis of the cylinder. These figures apply to position 1 of the pole distance of the electromagnet.

If experiments on configuration $4(\mathrm{~b})$ are compared to calculations according to eq (12), the agreement is not good. The same applies to experiments on configuration 4(c) and 4(d) compared to calculations according to eq (11).

In the calculations it is assumed that, in configuration 4(c), the mean displacement of the rim of the cylinder will be measured and the same assumption applies to the mean
TABLE 1-VALUES OF MAGNETIC INDUCTION AS A FUNCTION OF POLE DISTANCE

\begin{tabular}{cccc}
$\begin{array}{c}\text { Position } \\
\text { Poles }\end{array}$ & $B_{1}(T)$ & $B_{0}(T)$ & $B_{\mathrm{o}} B_{1}\left(\dot{\mathrm{m} T} \mathrm{~T}^{2}\right)$ \\
\hline 1 & 0.0145 & 0.581 & 8.42 \\
2 & 0.0149 & 0.599 & 8.93 \\
3 & 0.0154 & 0.617 & 9.50 \\
4 & 0.0159 & 0.638 & 10.1 \\
5 & 0.0165 & 0.660 & 10.9 \\
6 & 0.0170 & 0.681 & 11.6 \\
7 & 0.0176 & 0.706 & 12.4 \\
8 & 0.0182 & 0.731 & 13.3 \\
9 & 0.0188 & 0.758 & 14.3 \\
10 & 0.0195 & 0.788 & 15.4 \\
11 & 0.0201 & 0.819 & 16.5
\end{tabular}

TABLE 2-COMPARISON OF CALCULATED AND MEASURED DISPLACEMENT OF A COPPER CYLINDER AS A FUNCTION OF POLE DISTANCE

\begin{tabular}{cccc}
\hline & \multicolumn{2}{c}{ Axial Displacement $(\mathrm{pm})$} \\
\cline { 2 - 3 } Position \\
Poles & Measured & Calculated & \\
\hline & & & \\
\hline & 8.05 & Ratio \\
\hline 2 & 8.53 & 8.27 & 1.03 \\
3 & 9.01 & 8.77 & 1.03 \\
4 & 9.68 & 9.33 & 1.04 \\
5 & 10.4 & 9.92 & 1.02 \\
6 & 11.1 & 10.7 & 1.03 \\
7 & 12.0 & 11.4 & 1.03 \\
8 & 12.6 & 12.2 & 1.02 \\
9 & 13.7 & 13.1 & 1.04 \\
10 & 14.8 & 14.0 & 1.03 \\
& & 15.1 & 1.02 \\
& & &
\end{tabular}

TABLE 3-COMPARISON OF CALCULATED AND MEASURED DISPLACEMENT OF SOLID CYLINDERS OF DIFFERING MATERIALS

\begin{tabular}{|c|c|c|c|c|c|}
\hline$\left(10^{-8} \mathrm{Qm}\right)$ & $\begin{array}{c}E \\
\left(10^{10} \mathrm{Nm}^{-2}\right)\end{array}$ & $\nu$ & $\begin{array}{l}\text { Axial Displa } \\
\frac{1}{14} \\
\text { Meneasured }\end{array}$ & Sement (pm) & Ratio \\
\hline $\mathrm{Cu} 1: 67$ & 12.4 & 0.35 & 9.16 & 9.35 & 1.02 \\
\hline Au 2.19 & 7.9 & 0.42 & 5.07 & 4.77 & 0.94 \\
\hline $\mathrm{Sn} 11.5$ & 5.0 & 0.33 & 3.40 & 3.13 & 0.92 \\
\hline Al 2.65 & 7.02 & 0.34 & 10.5 & 10.0 & 0.95 \\
\hline
\end{tabular}

displacement of the central part of the cylinder in configuration 4(d).

In the case of configuration $4(\mathrm{~b})$, the discrepancy is mainly due to the elastic properties of the mirror, while in configurations 4(d) the assumptions of plane strain or plane stress are the main origins of discrepancy between calculation and measurement. To overcome this difficulty, a finite-element calculation is made of the displacement $u_{z}$ as a function of the radius $r$ of the solid cylinder of configuration 4(a). The results are shown in Fig. 3 and Table 4. The displacement in the case of configuration 4(b) is also calculated by the finite-element method. In this analysis, the elastic properties of the mirror are also 
Fig. 5-Frequency dependence of the axial displacement $u_{z}$ of a cylindrical single crystal of copper

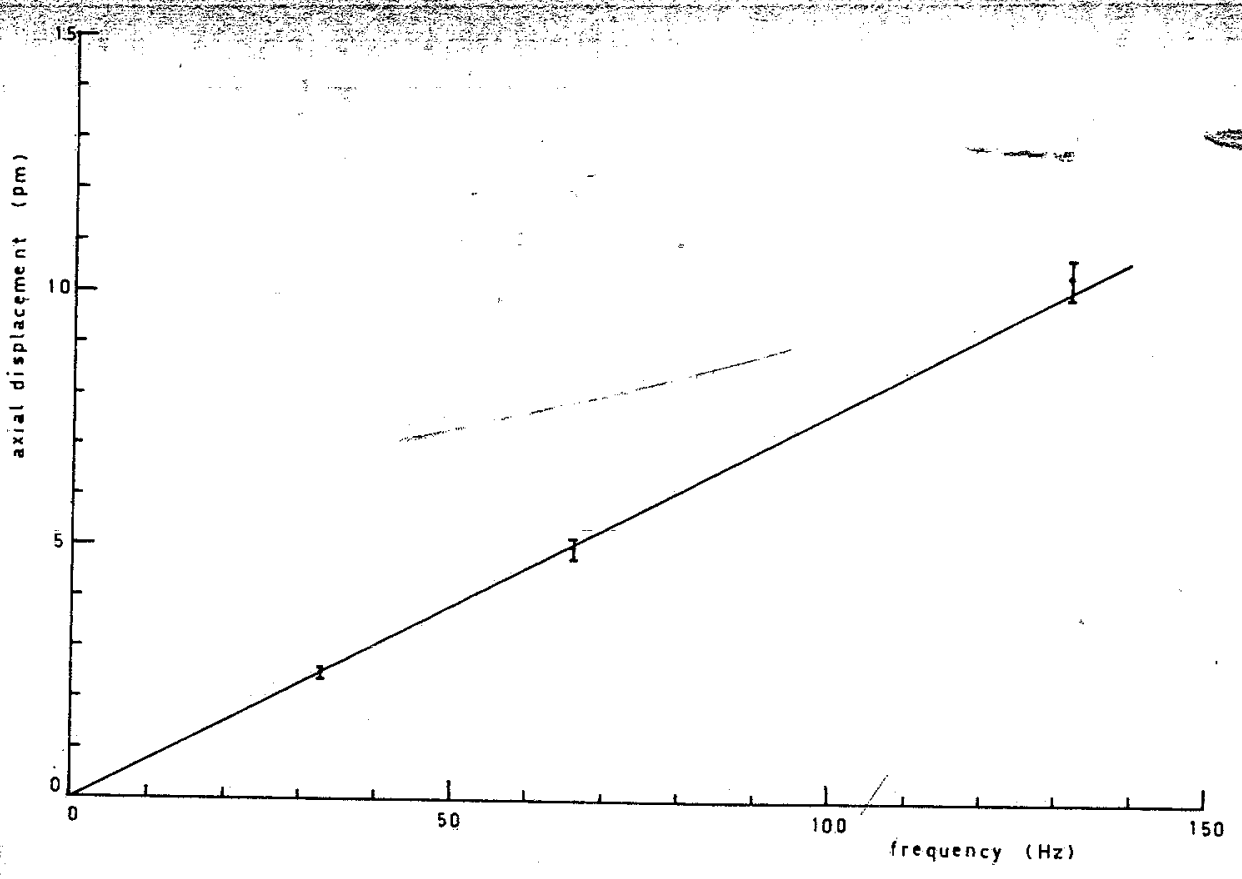

taken into account. These are: $E=6 \times 10^{10} \mathrm{Nm}^{-2}$ and $\nu=0.24$. The results are shown in Table 4 .

\section{Influence of the Skin Effect}

The skin effect is the limitation of the penetration of electromagnetic waves in a conducting material. As a result, the field strength and, thus; the currents induced in the cylindrical sample will not show a linear dependence on radius $r$.

In many cases, the skin effect is expressed in terms of the skin depth $d$, giving the decay of an electromagnetic wave to its $e^{-1}$ value where it penetrates a conducting medium. ${ }^{3}$ The skin depth $d=\sqrt{\frac{2 Q}{\omega \mu}}$ for copper at a frequency of $66 \mathrm{~Hz}$ equals $14 \mathrm{~mm}$. As the dimensions of the sample are of the same order of magnitude, an accurate calculation is necessary. The nonlinearity in the field strength $E_{\theta}$ will be determined by calculating the deviation of $E_{\theta}$ at the surface of the cylinder from its value found in eq (2).

Maxwell's equations read:

$$
\begin{aligned}
\nabla \times \bar{H}=\frac{\bar{E}}{\varrho} & \nabla \cdot \bar{E}=0 \\
\nabla \times \bar{E}=-\frac{\partial \bar{H}}{\partial t} & \nabla \cdot \bar{H}=0
\end{aligned}
$$

TABLE 4-COMPARISON OF CALCULATED AND MEASURED DISPLACEMENT OF COPPER IN DIFFERENT

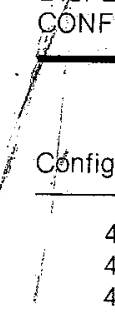

Axial Displacement $(\mathrm{pm})$

\begin{tabular}{ccc}
\cline { 2 - 3 } Cónfiguration & Measured & Calculated \\
\hline $4 b$ & 24.1 & 24.07 \\
$4 c$ & 9.37 & 9.42 \\
$4 d$ & 113 & 11.58
\end{tabular}

The divergence of $\bar{E}$ and $\bar{H}$ are chosen as zero because a solution is sought inside a homogeneous conductor. having no free electric or magnetic charges.

Cylinder coordinates are used as defined in Fig. 1 . The $r-, \theta$ - and $z$-components of the Maxwell equations in cylinder coordinates are :

$$
\begin{aligned}
& \frac{1}{r} \frac{\partial H_{z}}{\partial \theta}- \frac{\partial H_{\theta}}{\partial z}=\frac{E_{r}}{\varrho} \cdot \frac{1}{r} \frac{\partial E_{i}}{\partial \theta}-\frac{\partial E_{\theta}}{\partial z}=-\mu \frac{\partial H_{r}}{\partial t} \\
& \frac{\partial H_{r}}{\partial z}-\frac{\partial H_{z}}{\partial r}=\frac{E_{\theta}}{\partial z}-\frac{\partial E_{r}}{\partial r}=-\mu \frac{\partial H_{\theta}}{\partial t} \\
& \frac{1}{r}\left\{\frac{\partial}{\partial r}\left(r H_{\theta}\right)-\frac{\partial H_{r}}{\partial \theta}\right\}=\frac{E_{z}}{\varrho} \\
& \frac{1}{r}\left\{\frac{\partial}{\partial r}\left(r E_{\theta}\right)-\frac{\partial E_{r}}{\partial \theta}\right\}=-\frac{\partial H_{z}}{\partial t}
\end{aligned}
$$

From symmetry, we find $\frac{\partial}{\partial \theta}=0$ and, if we neglect the influence of the finite length of the sample, we can state $\frac{\partial}{\partial z}=0$. The set of equations reduces to

$$
\begin{gathered}
E_{r}=0 \quad H_{r}=0 \\
-\frac{\partial H_{z}}{\partial r}=\frac{E_{\theta}}{\varrho}-\frac{\partial E_{z}}{\partial r}=\mu \frac{\partial H_{\theta}}{\partial t} \\
\frac{1}{r} \frac{\partial}{\partial r}\left(r H_{\theta}\right)=\frac{E_{z}}{\varrho} \frac{1}{r} \frac{\partial}{\partial r}\left(r E_{\theta}\right)=-\mu \frac{\partial H_{z}}{\partial t}
\end{gathered}
$$

In order to find the dependence of $E_{\theta}$ on $H_{z}$, the second and sixth equation are combined. Eliminating $E_{\theta}$ and assuming a purely sinusoidal behavior of the field strength leads to the differential equation

$$
\begin{gathered}
\frac{\partial^{2} H_{z}}{\partial r^{2}}+\frac{1}{r} \frac{\partial H_{z}}{\partial r}-\frac{j \omega \mu H_{z}}{\varrho}=0 \text { and if we put } p^{2}=-\frac{j \omega \mu}{\varrho} \\
\frac{\partial^{2} H_{z}}{\partial r^{2}}+\frac{1}{r} \frac{\partial H_{z}}{\partial r}+p^{2} H_{z}=0
\end{gathered}
$$

This is a zero-order. Bessel function with argument $p r$, 
so that the general solution is

$$
H_{z}=C J_{o}(p r)
$$

and, as $E_{\theta}=-\varrho \frac{\partial H_{z}}{\partial r}$

$$
E_{\theta}=-p C Q J_{1}(p r)
$$

The integration constant $C$ may be found from the consideration that $H_{z}=H_{1}$ if $r=r_{o}$, so that

$$
\begin{gathered}
H_{1}=C J_{o}\left(p r_{o}\right) \text { and thus } \\
H_{z}=H_{1} \frac{J_{o}(p r)}{J_{o}\left(p r_{o}\right)}
\end{gathered}
$$

and

$$
E_{\theta}=-p_{Q} \frac{J_{1}(p r)}{J_{\circ}\left(p r_{\circ}\right)}
$$

Expecting small values for the argument $p r$, a powerseries expansion for $J_{o}(p r)$ and $J_{1}(p r)$ can be used. ${ }^{3}$

$$
\begin{gathered}
J_{0}(p r)=1-\frac{(p r)^{2}}{4}+\frac{(p r)^{4}}{64}-\ldots \ldots \\
J_{1}(p r)=\frac{p r}{2}\left\{1-\frac{(p r)^{2}}{8}+\frac{(p r)^{4}}{192}-\ldots \ldots\right\}
\end{gathered}
$$

$E_{\theta}$ can now be written as

$$
E_{\theta}=-\frac{p^{2} r \varrho}{2} \frac{\frac{(p r)^{2}}{8}+\frac{(p r)^{4}}{192}}{1-\frac{\left(p r_{0}\right)^{2}}{4}+\frac{\left(p r_{0}\right)^{4}}{64}} H_{1}
$$

If only the zero-order terms of this expansion are taken, then

$$
E_{\theta}=-\frac{p^{2} r_{\varrho}}{2} H_{1}=\frac{j \omega \mu}{2} r H_{1}=\frac{\mu r}{2} \frac{\partial B_{1}}{\partial t},
$$

as expected.

Using numerical values:

$$
\begin{aligned}
& \omega=2 \pi \times 66 \mathrm{rads}^{-1} \\
& \mu=4 \pi \times 10^{-7} \mathrm{As} \mathrm{V}^{-1} \mathrm{~m}^{-1} \\
& \varrho=1.67 \times 10^{-8} \Omega \mathrm{m} \\
& r_{\circ}=2.5 \times 10^{-3} \mathrm{~m}
\end{aligned}
$$

As the error is greatest at $r=r_{o}$, we calculate the value of $E_{\theta}$ in this point:

$$
\begin{gathered}
E_{\theta}=\frac{j \omega \mu r_{0} H_{1}}{2}\left\{\frac{1+j 0.0244-1.98 \times 10^{-4}}{1+j 0.0488-5.94 \times 10^{-4}}\right\} \\
E_{\theta}=\frac{j \omega \mu}{2} r_{0} H_{1} \times 0.9988
\end{gathered}
$$

From this result it can be concluded that the skin effect is of no influence on the previous comparison between measured and calculated values.

\section{Discussion and Conclusion}

From the foregoing sections, it follows that the interferometric measurement of strains resulting from eddy currents offers a new way to determine the elastic properties of conductive materials. Although the ultra- sonic-velocity method of measuring elastic properties is very well established and a great deal of work has been done to refine and optimize it, a comparison of this new method with the ultrasonic one is made as both of them have the advantage that only small pieces of materials in the order of $10^{-6} \mathrm{~m}^{3}$ are needed. It must be admitted that the absolute accuracy obtainable with the ultrasonic method is much better. It will be quite difficult to increase the accuracy of the new method to better than 1 percent due to the number of variables involved and the required accuracy of their measurement. A second drawback of the new method is that it measures the quotient of Poisson's ratio and Young's modulus. This may be overcome by looking for a configuration where these constants appear in different combinations in the formulas. From the plane-strain calculation it "follows that for a solid cylinder the radial displacement

$$
u_{r}=-\frac{(1+\nu)(1-2 \nu)}{8(1-\nu) E} B_{0} \frac{\partial B_{1}}{\partial t} b^{2} l,
$$

implying that a measurement of $u_{r}$ gives a second independent relation between $\nu$ and $E$. This, however, is not satisfactory because the plane strain calculation is an approximation. From the finite-element method it was found that the radial displacement $u_{r}$ at the free end of the solid cylinder is proportional to $1 / \nu E$. Both Poisson's ratio and Young's modulus can be determined in this way, although the measurements were not carried out in the present instance.

The main advantage of the new method is that the demands on surface flatness are quite low.

While the surfaces of the ultrasonic sample have to be flat and parallel to within at least one tenth of the ultrasonic wavelength, which equals $15 \mu \mathrm{m}$ for $30 \mathrm{MHz}$ longitudinal waves in copper; the new method demands only that the dimensions of the sample can be determined to an accuracy of about 1 percent.

A second advantage of the new method compared to the ultrasonic one, is in the use of low frequencies. Although, in general, no dispersion takes place, the difficulties encountered with the ultrasonic method should be mentioned in the case of ferrites, where the movement of Bloch walls affects the elastic properties, these walls being too slow to respond to the ultrasonic signals.

A general conclusion is that the new method can be used in those special cases where the ultrasonic method is not applicable.

\section{Acknowledgment}

The authors wish to express their gratitude to W.M.M.M. v.d. Eijnden for his valuable technical assistance in the performance of the displacement measurements; to F.A.J.A. Potters for performing the ultrasonic-velocity measurements and to W.A.M. Brekelmans and J.D. Janssen of the Technical Mechanics group for their valuable remarks.

\section{References}

1. Kwaaitaal, Th., "Contribution to the interferometric measurement of sub-Angstrom vibrations," Rev. Sc. Instrum. 45 (1), 39-4I (Jan. 1974).

2. Kwaaitaal, Th., "The measurement of small magnetostrictive effects by an interferometric method," $J$. of Magnetism and Magnetic Materials; 6, 290-294 (1977).

3. King, Ronald W.P., "Fundamental Electromagnetic Theory," Dover (1963).

4. Abramowitz, M., "Handbook of Mathematical Functions," Dover (1965). 